\title{
A role for ATP Citrate Lyase in cell cycle regulation during myeloid differentiation
}

Jess Rhee ${ }^{1,2}$, Lauren A. Solomon ${ }^{1,2}$, and Rodney P. DeKoter ${ }^{1,2}$

${ }^{1}$ Department of Microbiology \& Immunology and the Centre for Human Immunology, Schulich School of Medicine \& Dentistry, Western University, London, Ontario, Canada N6A 5C1.

${ }^{2}$ Division of Genetics and Development, Children's Health Research Institute, Lawson Research Institute, London, Ontario, Canada N6C 2R5.

Correspondence: Rodney P. DeKoter, Department of Microbiology \& Immunology, Schulich School of Medicine \& Dentistry, Western University, London, Ontario, Canada N6A 5C1. Phone: (519) 661-2084; Fax: (519) 661-3499; E-mail address: rdekoter@uwo.ca 


\section{Abstract}

2 Differentiation of myeloid progenitor cells into macrophages is accompanied by increased

3 PU.1 concentration and increasing cell cycle length, culminating in cell cycle arrest. Induction of

4 PU.1 expression in a cultured myeloid cell line expressing low PU.1 concentration results in

5 decreased levels of mRNA encoding ATP-Citrate Lyase (ACL) and cell cycle arrest. ACL is an

6 essential enzyme for generating acetyl-CoA, a key metabolite for the first step in fatty acid

7 synthesis as well as for histone acetylation. We hypothesized that ACL may play a role in cell

8 cycle regulation in the myeloid lineage. In this study, we found that acetyl-CoA or acetate

9 supplementation was sufficient to rescue cell cycle progression in cultured BN cells treated with

10 an ACL inhibitor or induced for PU.1 expression. Acetyl-CoA supplementation was also sufficient

11 to rescue cell cycle progression in BN cells treated with a fatty acid synthase (FASN) inhibitor.

12 We demonstrated that acetyl-CoA was utilized in both fatty acid synthesis and histone acetylation

13 pathways to promote proliferation. Finally, we found that Acly mRNA transcript levels decrease

14 during normal macrophage differentiation from bone marrow precursors. Our results suggest that

15 regulation of ACL activity is a potentially important point of control for cell cycle regulation in

16 the myeloid lineage. 


\section{Introduction}

Highly proliferating cells, including cancers, preferentially use glycolysis over oxidative phosphorylation because, although it is less efficient at generating ATP, glycolysis is rapid and provides key metabolites for several biosynthetic pathways including nucleotide, amino acid, and fatty acid synthesis (1). This preferential use of glycolysis by cancer cells is known as the Warburg effect $(1,2)$. Glycolysis results in the production of citrate that can be exported from mitochondria to serve as the substrate for synthesis of acetyl-CoA by the enzyme ATP Citrate Lyase (ACL) (3). Acetyl-CoA is the required substrate of fatty acid synthase (FASN) in the first step of de novo fatty acid synthesis. Although normal cells and cancer cells can utilize exogenous lipids, FASNmediated fatty acid synthesis is required to sustain the needs of highly proliferative cells (4). Many cancer types display increased endogenous fatty acid biosynthesis, regardless of the levels of extracellular lipids available (5). Inhibiting FASN is effective in limiting the growth and proliferation of cancer cells $(4,6)$.

As a central metabolite, there are several anabolic and catabolic pathways that can lead to the production of acetyl-CoA. These pathways can be located in mitochondria or in the cytoplasm (7). Within the mitochondria, acetyl-CoA is generated in the matrix by the pyruvate dehydrogenase complex, $\beta$-oxidation of fatty acids, and the catabolic metabolism of branched amino acids (7). In the cytoplasm, ACL is the central enzyme for production of acetyl-CoA from citrate. Acetyl-CoA synthetase 2 (ACSS2) can also generate acetyl-CoA from the substrate acetate that can be produced in the cell or imported into the cell (8).

Acetyl-CoA links lipid metabolism and histone acetylation to proliferation by being the midpoint in these two processes, with ACL produced acetyl-CoA diverted into both the fatty acid biosynthesis and histone acetylation pathways $(9,10)$. In addition to lipid biosynthesis, histone acetylation is also important for proliferation $(9,10)$. ACL is found in both the nucleus and 
41 cytoplasm, and RNA-interference-mediated silencing of ACL significantly reduces global histone

42 acetylation (9). ACL is known to be upregulated in many cancers, and inhibition of ACL inhibits

43 cancer cell proliferation (11-15). Therefore, ACL has an essential position in cellular processes,

44 particularly lipid biosynthesis and histone acetylation, both of which influence cell cycle

45 progression and proliferation $(3,9,16)$.

PU.1 is a member of the E26-transformation-specific (ETS)-family of transcription factors

47 and is essential for myeloid development $(17,18)$. PU.1 is expressed in hematopoietic stem cells

48 (HSCs) and is further upregulated during myeloid differentiation $(19,20)$. Inhibition of PU.1

49 function in HSCs blocks subsequent myeloid differentiation (19, 21). During macrophage

50 differentiation, PU.1 protein accumulates, correlating with increasing cell cycle length (22).

51 Conversely, multiple studies have shown that decreased expression of PU.1 leads to increased cell

52 cycle progression and eventually acute myeloid leukemia (AML) in mice (23-25). Our laboratory

53 showed that cell cycle progression is inhibited by induction of PU.1 expression in a cultured

54 myeloid cell line expressing low PU.1 concentration $\left(\operatorname{Spil}^{\mathrm{BN} / \mathrm{BN}}\right)(25,26)$. Induction of PU.1 in

55 inducible cells (iBN cells) resulted in macrophage differentiation and induction of microRNAs

56 that targeted acetyl-CoA metabolism including Acly encoding ACL (27). We found that chemical

57 inhibition of ACL activity was sufficient to block cell cycle progression in cultured BN cells (27).

58 The goal of the current study was to explore the mechanism(s) by which cell cycle is

59 regulated in cultured BN cells through control of ATP Citrate Lyase (ACL) activity. We found

60 that acetyl-CoA or acetate supplementation was sufficient to rescue cell cycle progression in

61 cultured BN cells treated with an ACL inhibitor or induced for PU.1 expression. Acetyl-coA

62 supplementation was also sufficient to rescue cell cycle progression in BN cells treated with a

63 FASN inhibitor. Through lipid and histone extraction, we demonstrated that acetyl-CoA was

64 utilized in both fatty acid synthesis and histone acetylation pathways to promote proliferation. 
65 However, in ACL inhibited cells, there was an increase in the amount of acetyl-CoA incorporated

66 into lipids, suggesting that lipid biosynthesis may be a crucial pathway to promote proliferation.

67 Finally, we found that Acly mRNA transcript levels decrease during normal macrophage

68 differentiation from bone marrow precursors. Our results suggest that regulation of ACL activity

69 is a potentially important point of control for cell cycle regulation in the myeloid lineage. 
71 Mice

72

73

74

75

76

77

78

79

80

81

82

83

84

85

86

87

88

89

90

91

92

93

\section{Methods}

C57BL/6 mice were purchased from Charles River Laboratories (Saint-Constant, QC, Canada). All experiments were performed on protocols approved by the Western University Council on Animal Care.

\section{Cell culture}

The $\mathrm{BN}$ and $\mathrm{iBN}$ inducible cell lines were previously described $(25,27)$. BN cells were cultured in Iscove's modified Dulbecco's medium (IMDM) (Wisent, St-Bruno, QC), with 1 ng/ml GM-CSF (Peprotech, QC), and additionally supplemented with 10\% fetal bovine serum (FBS) (Wisent, St-Bruno, QC), penicillin (100 U/ml)/streptomycin (100 $\mu \mathrm{g} / \mathrm{ml})$ (Mediatech, Manassas, VA), L-glutamine (2 mmol/L) (Mediatech), 2-mercaptoethanol (5 x 10-5 M) (Sigma-Aldrich, St. Louis, MO). PU.1 induction experiments were performed by culture of iBN cells in $1.0 \mathrm{ng} / \mathrm{ml} \mathrm{GM-}$ CSF in the presence of absence of $1000 \mathrm{ng} / \mathrm{ml}$ doxycycline for 48 hours. Additionally, BN/iBN cells were cultured in the presence or absence of $100 \mu \mathrm{M}$ of acetyl-CoA (Sigma Aldrich, Oakville,

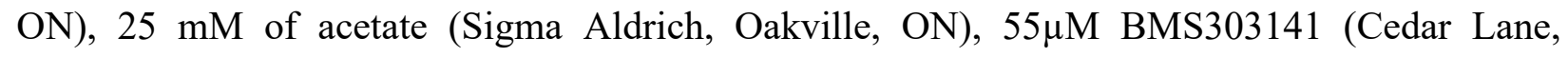
Burlington, ON), or $10 \mu \mathrm{g} / \mathrm{ml}$ of $\mathrm{C} 75$ (Sigma Aldrich, Oakville, ON). Platinum-E (Plat-E) retroviral packaging cells were cultured in Dulbecco's modified Eagle's medium (DMEM; Wisent) supplemented with $10 \%$ fetal bovine serum (FBS) (Wisent), penicillin (100 $\mathrm{U} / \mathrm{ml}$ )/streptomycin (100 $\mu \mathrm{g} / \mathrm{ml})$ (Mediatech), and L-glutamine (2mmol/L) (Mediatech).

\section{Cell Cycle Analysis}

Cell cycle was analyzed by flow cytometry with an allophycocyanin (APC) BrdU Flow Kit according to the manufacturer's protocol (BD Biosciences, Mississauga, ON). Cells were labeled 
94 with bromodeoxyuridine (BrdU) for 2 hours at $37^{\circ} \mathrm{C}$. Cells were then incubated with the APC95 conjugated anti-BrdU antibody using a 1:100 dilution. Cells were additionally stained with 7amino-actinomycin D (7-AAD; BD Pharmingen) to determine cell cycle position. To stain cells

97 with 7-AAD, cells were suspended in Dulbecco's phosphate buffered saline (DPBS) supplemented with $5 \mathrm{mM}$ ethylenediaminetetraacedic acid (EDTA) and $0.5 \%$ bovine serum albumin (BSA) and 99 then incubated with 7-AAD.

100

Flow Cytometry

Flow cytometry analysis was performed on single-cell suspensions of cells washed in flow 103 cytometry buffer consisting of DPBS supplemented with $0.5 \mathrm{mM}$ EDTA and $0.5 \%$ BSA. 104 Antibodies directly conjugated to phycoerythrin (PE) against CD11b and C-kit were utilized to 105 determine lineage-negative characteristics of extracted bone marrow cells. APC-BrdU was utilized 106 for cell cycle analysis. Flow cytometric analysis and sorting was performed using a FACSCanto 107 and FACSAria III, respectively (BD Immunocytometry Systems, San Jose, CA) at the London 108 Regional Flow Cytometry Facility. Data was analyzed using FlowJo, version 10 (Tree Star, 109 Ashland, OR).

\section{Retrovirus Production}

Plat-E retroviral packaging cells (28) were used to generate retroviral supernatants using 113 PEIPro transfection reagent (Polyplus, Ullkirch, France) at a 3:1 PEIPro/DNA ratio. Supernatant 114 containing virus was collected 48 hours after transfection. Cells were infected by spinoculation by 115 centrifugation at $3000 \mathrm{rpm}$ for 3 hours at $32^{\circ} \mathrm{C}$ with polybrene at a final concentration of $8 \mu \mathrm{g} / \mathrm{ml}$. 116 After centrifugation, cells were washed and cultured for 48 hours to allow for retroviral integration 
117 and gene expression. Infection frequency was determined by flow cytometric analysis of green

118 fluorescent protein (GFP).

119

Bone Marrow Cell Isolation and Culture

Bone marrow cells were extracted from the femurs and tibias of $\mathrm{C} 57 \mathrm{~B} 1 / 6$ mice. Bone marrow cells were washed three times with DPBS supplemented with $0.5 \mathrm{mM}$ EDTA and 0.5\% Mississauga, ON), and analyzed by flow cytometry. Lin` bone marrow cells were grown in culture with complete IMDM medium supplemented with 10 ng/ml M-CSF (Peprotech, QC).

\section{Tritium Culture and Scintillation Counting}

BN cells were cultured with $0.5 \mu \mathrm{Ci}$ of $\left[{ }^{3} \mathrm{H}\right]$-acetyl-CoA (Perkin Elmer, Waltham, MA) in $1 \mathrm{~mL}$ of complete media for 24 hours. Media was collected in separate tubes and the pellets were washed three times with PBS. The cell pellets were fully solubilized with $200 \mu 1$ of a 3\% solution using $1 \mathrm{ml}$ of a 2:1 (v/v) chloroform:methanol solution, similar to the Folch method (without the 
141 scintillation counter (Beckman Coulter, Ramsey, MN) using $10 \mu 1$ from either solubilized cell

142 pellets, lipid extracts and histone extracts.

143

144 Reverse Transcriptase Quantitative PCR

145 RNA was isolated from cells using TRIzol Reagent (Life Technologies, Carlsbad, CA) and 146 reverse-transcribed into cDNA using the iScript kit (Bio-Rad, Hercules, CA). Quantitative PCR 147 (qPCR) was performed using iQ SYBR Green Supermix Kit (Bio-Rad) and a QuantStudio5

148 instrument (Applied Biosystems, Foster City, CA). Relative messenger RNA (mRNA) levels of 149 Acly were normalized to $B 2 m$ or Adgrel as reference genes and compared between samples using 150 the comparative threshold cycle method (31). Primer sequences are listed in Supplemental Table 1511.

152

153 Statistical Analysis

154 Statistical significance was determined with ratio-paired $t$ test or one-way analysis of 155 variance (ANOVA) with Tukey's multiple comparison using Prism 5 (GraphPad Software, La 156 Jolla, CA, USA). 


\section{Results}

158 Supplementation with acetyl-CoA or acetate rescues cell cycle arrest induced by inhibition of ATP

159

160

161

162

163

164

165

166

167

168

169

170

171

172

173

174

175

176

177

178

179

180

\section{Citrate Lyase in cultured myeloid cells}

$\mathrm{BN}$ cells are myeloid precursor cells that are impaired for differentiation as a consequence of low PU.1 expression, and proliferate continuously in culture in response to granulocytemacrophage colony-stimulating factor $(\mathrm{GM}-\mathrm{CSF})(26,32)$. We previously showed that induction of PU.1 in inducible BN (iBN) cells resulted in downregulation of Acly encoding ATP Citrate Lyase (ACL), and that this regulation was likely indirectly mediated through induction of microRNAs (27). BMS303141 (BMS) is an effective inhibitor of ACL activity (33) and was sufficient to inhibit cell cycle progression in cultured BN cells (27). We set out to determine if supplementation of BN cells with acetyl-CoA could rescue BMS inhibition of cell cycle. BN cells were cultured with $55 \mu \mathrm{M}$ BMS, a concentration found to result in half-maximal cell cycle inhibition as determined by the frequency of cells in S-phase (Fig. 1A, B, and data not shown). Addition of $100 \mu \mathrm{M}$ acetyl-CoA to BMS-inhibited cultures resulted in a significant increase in the frequency of S-phase BN cells (Fig.1C, 1D). The sufficiency of acetyl-CoA to increase cell cycle progression of $\mathrm{BN}$ cells treated with BMS, suggests that this drug inhibits cell cycle progression by reducing the available cellular pool of acetyl-CoA.

Next, acetate was used as a supplement since exogenous sources of acetate are able to be transported into the cell by monocarboxylate transporters (34). Acetyl-CoA synthetase 2 (ACSS2) can metabolize acetate into acetyl-CoA (8). Supplementation with $25 \mathrm{mM}$ acetate significantly rescued proliferation of BN cells treated with $55 \mu \mathrm{M}$ BMS (Fig. 2). This result suggests that BN cells could convert acetate to acetyl-CoA via the ACSS2 pathway to bypass the block induced by BMS treatment. 
181

182

183

184

185

186

187

188

189

190

191

192

193

194

195

196

197

198

199

200

201

202

203

Supplementation with acetyl-CoA or acetate rescues cell cycle arrest induced by PU.1 induction in cultured myeloid cells

Our laboratory previously demonstrated that PU.1 induced iBN cells undergo cell cycle arrest accompanied by downregulation of Acly mRNA transcripts (27). Therefore, we wanted to determine if supplementing PU.1 induced iBN cells with acetyl-CoA or acetate was sufficient to rescue cell cycle arrest. Following induction of PU.1 in iBN cells with doxycycline, cell cycle progression was reduced (Fig. 3A, 2B). Supplementation with acetyl-CoA (Fig. 3C, 3D) and to a lesser extent acetate (Fig. 3E, 3F) significantly rescued PU.1-induced cell cycle arrest. These results suggest that PU.1 induces cell cycle arrest, at least in part, by down-regulation of production of acetyl-CoA.

\section{Acetyl-CoA rescues cell cycle arrest from impaired FASN function}

Given that acetate and acetyl-CoA supplementation were able to rescue cell cycle arrest from ACL inhibition via BMS and PU.1 induction via doxycycline, we next determined whether inhibition of fatty acid synthesis could arrest cell cycle in BN cells. C75 is an effective chemical inhibitor of FASN (35). Culture of BN cells with $10 \mu \mathrm{g} / \mathrm{ml} \mathrm{C75} \mathrm{efficiently} \mathrm{inhibited} \mathrm{cell} \mathrm{cycle}$ progression (Fig. 4A, 5B, 5D). Interestingly, supplementation of C75-treated BN cells with acetylCoA resulted in a significant rescue of cell cycle progression (Fig. 4C, 5D). This result suggests that inhibition of fatty acid synthesis is sufficient to impair cell cycle progression in cultured $\mathrm{BN}$ cells, and that supplementation with exogenous acetyl-CoA interferes with FASN inhibition by C75 to rescue fatty acid synthesis and cell cycle progression.

\section{Extracellular $\left[{ }^{3} \mathrm{H}\right]$-Acetyl-CoA is incorporated into cells in a regulated manner}


It has been shown that acetyl-CoA cannot enter cells by passive diffusion; and there are no descriptions of transporters that allow for import of extracellular acetyl-CoA (36). Therefore, we tested the import of extracellular acetyl-CoA into cells by the addition of extracellular $\left[{ }^{3} \mathrm{H}\right]$-acetylCoA followed by liquid scintillation counting. BN cells were cultured with $0.5 \mu \mathrm{Ci}$ of $\left[{ }^{3} \mathrm{H}\right]$-acetylCoA for 24 hours. After 24 hours, supernatants were collected and washed cell pellets were fully solubilized using 3\% KOH followed by liquid scintillation counting (29). Solubilized cell pellets of iBN cells incubated with $\left[{ }^{3} \mathrm{H}\right]$-acetyl-CoA incorporated a significant amount of ${ }^{3} \mathrm{H}$ compared to the negative control (Fig. 5A). As expected, most $\left[{ }^{3} \mathrm{H}\right]$-acetyl-CoA remained in the supernatant (Fig. 5A).

To determine if uptake of $\left[{ }^{3} \mathrm{H}\right]$-acetyl-CoA can be actively regulated, we determined if ACL inhibition affected $\left[{ }^{3} \mathrm{H}\right]$-acetyl-CoA incorporation. BN cells were cultured in media with 55 $\mu \mathrm{M}$ of BMS to inhibit ACL activity and $0.5 \mu \mathrm{Ci}$ of $\left[{ }^{3} \mathrm{H}\right]$-acetyl-CoA. Interestingly, culture with BMS resulted in a significant increase in the incorporation of $\left[{ }^{3} \mathrm{H}\right]$-acetyl-CoA in $\mathrm{BN}$ cells (Fig. 5B). This result suggests that the $\left[{ }^{3} \mathrm{H}\right]$-acetyl-CoA import mechanism is actively modulated by intracellular acetyl-CoA concentrations.

Next, we set out to determine if supplementation with acetate could affect uptake of $\left[{ }^{3} \mathrm{H}\right]-$ acetyl-CoA in BN cells. Interestingly, supplementation with $25 \mathrm{mM}$ acetate dramatically reduced the amount of $\left[{ }^{3} \mathrm{H}\right]$-acetyl-CoA incorporation by BMS-treated $\mathrm{BN}$ cells (Fig. 5C). In contrast, supplementation with $100 \mu \mathrm{M}$ acetyl-CoA did not significantly reduce the amount of $\left[{ }^{3} \mathrm{H}\right]$-acetylCoA incorporation by BMS-treated BN cells (Fig. 5C). These results suggest that acetate, but not exogenous acetyl-CoA, is sufficient to compensate for the need to import additional acetyl-CoA upon BMS inhibition. Taken together, these results suggest that BN cells actively take up and incorporate $\left[{ }^{3} \mathrm{H}\right]$-acetyl-CoA from the exogenous environment of the cells, and that 
227 supplementation with acetate results in production of enough acetyl-CoA to prevent detection of

228 this incorporation from the exogenous environment.

229

$\left[{ }^{3} H\right]$-Acetyl-CoA is incorporated into both lipids and histones acetylation to promote gene activation of genes involved in cell cycle regulation (9). To determine which of these two pathways is involved in acetyl-CoA incorporation, BN cells were incubated

237 for 24 hours with $0.5 \mu \mathrm{Ci}$ of $\left[{ }^{3} \mathrm{H}\right]$-acetyl-CoA. Lipids were enriched using the Folch extraction method (30) and histones were enriched using a histone extraction kit before liquid scintillation counting. The results showed that $\left[{ }^{3} \mathrm{H}\right]$-acetyl-CoA was incorporated into both lipids and histones, although quantitatively more was incorporated into lipids (Fig. 6A). This result suggests that both pathways may be active in $\mathrm{BN}$ cells, although lipid biosynthesis may be quantitatively more 242 important. performed lipid extraction on BN cells treated with or without BMS. The results showed that BMS treatment increased the amount of $\left[{ }^{3} \mathrm{H}\right]$-acetyl-CoA incorporation in lipids in $\mathrm{BN}$ cells compared

247 to cells not treated with BMS (Fig. 6C). This result suggests that when acetyl-CoA concentrations 248 are limiting, cells divert this molecule towards the pathway of lipid biosynthesis. Taken together, 
250 through decreased lipid biosynthesis, and inhibition can be partially reversed by the exogenous

251 addition of acetyl-CoA.

252

Decrease in Acly mRNA transcript levels during M-CSF-dependent macrophage differentiation

Finally, we wanted to determine whether Acly levels decrease during differentiation of myeloid progenitor cells into macrophages. If decreasing ACL levels are involved with decreasing cell cycle progression, then we would expect Acly mRNA transcript levels to decrease during macrophage differentiation. To test this idea, bone marrow cells from C57Bl/6 mice were prepared and lineage depleted (Lin-) using antibodies for CD11b, GR-1, B220, and TER119 to remove mature macrophages, granulocytes, B cells, and erythrocytes, respectively (Fig. 7A). CD11b myeloid cells were efficiently depleted in the Lin $^{-}$bone marrow cell fraction (Fig. 7B). Lin` cells were cultured in $10 \mathrm{ng} / \mathrm{ml} \mathrm{M-CSF}$ for 6 days. Adherent cells were detectable at day 2 and cells

262 with macrophage morphology were visible by days 4 and 6 (Fig. 7C). RNA was prepared from 263 adherent cells on days 2, 4, and 6. RT-qPCR analysis was performed to determine the steady-state 264 mRNA transcript levels for Acly relative to either B2m (encoding $\beta 2$ microglobulin) or Adgrel 265 (encoding F4/80) as reference genes. There was a significant decrease in the level of Acly mRNA 266 transcripts with reference to either B2m (Fig. 7D) or Adgrel (Fig. 7E). This observation suggests that mRNA transcript levels for Acly decrease during macrophage differentiation, consistent with a potential role in regulation of cell cycle progression in the myeloid lineage. 
271

272

273

274

275

276

277

278

279

280

281

282

283

284

285

286

287

288

289

290

291

\section{Discussion}

In this study, we showed that acetyl-CoA or acetate supplementation was sufficient to rescue cell cycle progression in cultured BN cells treated with BMS or induced for PU.1. AcetylCoA supplementation was sufficient to rescue cell cycle progression in cultured BN cells treated with C75. Through lipid and histone extraction, we were able to demonstrate that acetyl-CoA was utilized in both fatty acid synthesis and histone acetylation pathways to promote proliferation. In ACL inhibited cells there was an increase in the amount of acetyl-CoA incorporated into lipids, suggesting that lipid biosynthesis may be a crucial pathway to promote proliferation. Finally, we found that Acly mRNA transcript levels decrease during normal macrophage differentiation from bone marrow precursors. Our results suggest that downregulation of ACL activity is a potentially important point of control for cell cycle regulation in the myeloid lineage.

Acetate can be actively transported into cells and metabolized to acetyl-CoA by the enzyme acyl-CoA synthetase short-chain family member 2 (ACSS2) (8). However, there are no described mechanisms for active transport of acetyl-CoA (36). Acetyl-CoA transporters have been discovered in other subcellular compartments, notably acetyl-CoA transporters-1 (AT-1), which is expressed on the endoplasmic reticulum (ER) and mediated acetyl-CoA transport into the ER lumen (37-39). In our experiments we found that exogenous supplementation of cell culture media with acetyl-CoA could rescue cell cycle arrest by chemical inhibition of ACL or FASN. Furthermore, $\left[{ }^{3} \mathrm{H}\right]$ acetyl-CoA was incorporated into cellular lipids in a manner that was increased by inhibition of ACL. These results strongly suggest active transport of acetyl-CoA into cultured BN cells. Given that the AT-1 transporter is found to be localized on the ER, we speculate that AT-1 could be exported to the Golgi apparatus, and from the Golgi to the cell membrane (40). A second possibility is that acetyl-CoA enters BN cells through active phagocytosis or pinocytosis. 
292 BN cells express PU.1, although at low concentration, and the pattern of gene expression in these

293 cells suggests that they are immature myelomonocytic cells that are capable of phagocytosis (25).

294 An important question is whether either lipid biosynthesis or histone acetylation is the "sensor" to

295 signal for cell cycle regulation by ACL inhibition. BMS treated iBN cells had higher $\left[{ }^{3} \mathrm{H}\right]$-acetyl-

296 CoA incorporation in their lipids than histones, suggesting that lipid biosynthesis may be the

297 preferential pathway by which extracellular acetyl-CoA rescues iBN cells from cell cycle arrest.

298 Consistent with lipid synthesis being the predominant mechanism by which ACL inhibition blocks

299 cell cycle progression, one study utilized shRNA to silence Acly expression and showed reduced

300 proliferation in these Acly silenced cells when grown in reduced lipid conditions (14). This study

301 showed that supplementation with fatty acid, oleic acid, and acetate was sufficient to rescue cell

302 cycle (14). Therefore, taken together, these results suggest that acetyl-CoA as a supplement is able

303 to restore cell cycle progression in BMS treated BN cells by restoring the acetyl-CoA available in

304 these cells for lipid biosynthesis to allow for cell cycle progression.

Previous studies suggested a link between PU.1 concentration and regulation of cell cycle progression. Small reductions in PU.1 concentration lead to increased proliferation and reduced differentiation of hematopoietic stem cells and myeloid progenitor cells $(24,26,41)$. Reintroduction of PU.1 into proliferating cells expressing low PU.1 concentration rapidly induces cell cycle arrest and differentiation $(23,25)$. Induction of cell cycle arrest by PU.1 is accompanied by reduced Acly mRNA transcript levels (27). We showed in the current study that Acly mRNA transcript levels also decreased during normal M-CSF-dependent macrophage differentiation (Fig. 8). Therefore, we speculate that macrophage differentiation from myeloid progenitors involves several feedback loops involving PU.1 and Acly. Reduced Acly mRNA and ACL protein levels

314 would lead to increased cell cycle length due to reduced lipid biosynthesis. Increased cell cycle 315 length promotes PU.1 protein accumulation (22). High PU.1 concentration would then promote 
316 macrophage differentiation as marked by increased expression by genes such as Adgrel and 317 expression of microRNAs targeting Acly (27). This would feed back to further decrease ACL levels 318 to promote cell cycle arrest and macrophage differentiation.

319 In conclusion, it is well documented that nutrient depletion impairs cell cycle progression

320 in normal or cancerous cells. However, there is still little known about the sensor(s) that transmit 321 information about nutrient status to the cell cycle clock $(42,43)$. Our results suggest that regulation 322 of the acetyl-CoA pool in cells may be an important mechanism to control cell cycle in developing 323 myeloid cells. The size of the acetyl-CoA pool can be sensed by multiple mechanisms including 324 through the rate of lipid biosynthesis or by histone acetylation (44). An important future direction 325 will be to further explore the pathway by which the size of the intracellular pool of acetyl-CoA 326 regulates the cell cycle clock in myeloid cells. 


\section{Acknowledgements}

328 We thank Kristin Chadwick and the London Regional Flow Cytometry Core Facility for

329 assistance with flow cytometric analysis. We thank Drs. Murray Huff and Bryan Heit (Western

330 University) for helpful advice and discussion. This work was supported by a Canada Graduate

331 Scholarship-Masters to J.R. and by a Natural Sciences and Engineering Research Council

332 Discovery Grant to R.D. (Grant 04749-2010). 


\section{References}

1. Lunt, S. Y., and M. G. Vander Heiden. 2011. Aerobic Glycolysis: Meeting the Metabolic Requirements of Cell Proliferation. Annu. Rev. Cell Dev. Biol. 27: 441-464.

2. Warburg, B. Y. O. 1956. On the origin of cancer cells. Science (80-. ). 123: 309-314.

3. Shi, L., and B. P. Tu. 2015. Acetyl-CoA and the regulation of metabolism: Mechanisms and consequences. Curr. Opin. Cell Biol. 33: 125-131.

4. Rohrig, F., and A. Schulze. 2016. The multifaceted roles of fatty acid synthesis in cancer. Nat. Rev. Cancer 16: 732-749.

5. Menendez, J. A., and R. Lupu. 2007. Fatty acid synthase and the lipogenic phenotype in cancer pathogenesis. Nat. Rev. Cancer 7: 763-777.

6. Flavin, R., S. Peluso, P. Nguyen, and M. Loda. 2010. Fatty acid synthase as a potential therapeutic target in cancer. Futur. Oncol. 6: 551-562.

7. Pietrocola, F., L. Galluzzi, J. M. Bravo-San Pedro, F. Madeo, and G. Kroemer. 2015. Acetyl coenzyme A: A central metabolite and second messenger. Cell Metab. 21: 805-821.

8. Schug, Z. T., J. Vande Voorde, and E. Gottlieb. 2016. The metabolic fate of acetate in cancer. Nat. Rev. Cancer 16: 708-717.

9. Wellen, K. E., G. Hatzivassiliou, U. M. Sachdeva, T. V Bui, J. R. Cross, and C. B. Thompson. 2009. ATP-citrate lyase links cellular metabolism to histone acetylation. Science (80-. ). 324 :

1076-1080.

10. Cai, L., B. M. Sutter, B. Li, and B. P. Tu. 2011. Acetyl-CoA induces cell growth and proliferation by promoting the acetylation of histones at growth genes. Mol Cell 42: 426-437. 11. Hatzivassiliou, G., F. Zhao, D. E. Bauer, C. Andreadis, A. N. Shaw, D. Dhanak, S. R. Hingorani, D. A. Tuveson, and C. B. Thompson. 2005. ATP citrate lyase inhibition can suppress tumor cell growth. Cancer Cell 8: 311-321. 

citrate lyase is an important component of cell growth and transformation. Oncogene 24: 63146322.

13. Wang, D., L. Yin, J. Wei, Z. Yang, and G. Jiang. 2017. ATP citrate lyase is increased in

361 human breast cancer, depletion of which promotes apoptosis. Tumor Biol. 39:

362101042831769833.

363 14. Zaidi, N., I. Royaux, J. V. Swinnen, and K. Smans. 2012. ATP Citrate Lyase Knockdown

364 Induces Growth Arrest and Apoptosis through Different Cell- and Environment-Dependent

365 Mechanisms. Mol. Cancer Ther. 11: 1925-1935.

366 15. Khwairakpam, A. D., M. S. Shyamananda, B. L. Sailo, S. R. Rathnakaram, G. Padmavathi, J.

367 Kotoky, and A. B. Kunnumakkara. 2015. ATP citrate lyase (ACLY): a promising target for

368 cancer prevention and treatment. Curr. Drug Targets 16: 156-63.

369 16. Cai, L., and B. P. Tu. 2011. On acetyl-CoA as a gauge of cellular metabolic state. Cold

370 Spring Harb. Symp. Quant. Biol. 76: 195-202.

371 17. Scott, E. W., M. C. Simon, J. Anastasi, and H. Singh. 1994. Requirement of transcription

372 factor PU.1 in the development of multiple hematopoietic lineages. Science (80-. ). 265: 1573-

3731577.

374 18. Turkistany, S. A., and R. P. Dekoter. 2011. The transcription factor PU.1 is a critical

375 regulator of cellular communication in the immune system. Arch. Immunol. Ther. Exp. (Warsz).

37659.

377 19. Voso, M. T., T. C. Burn, G. Wulf, B. Lim, G. Leone, and D. G. Tenen. 1994. Inhibition of

378 hematopoiesis by competitive binding of transcription factor PU.1. Proc. Natl. Acad. Sci. U. S.

379 A. 91: 7932-6.

380 20. Nutt, S. L., D. Metcalf, A. D’Amico, M. Polli, and L. Wu. 2005. Dynamic regulation of PU.1 
expression in multipotent hematopoietic progenitors. J Exp Med 201: 221-231.

21. Cheng, T., H. Shen, D. Giokas, J. Gere, D. G. Tenen, and D. T. Scadden. 1996. Temporal mapping of gene expression levels during the differentiation of individual primary hematopoietic cells. Proc. Natl. Acad. Sci. U. S. A. 93: 13158-63.

22. Kueh, H. Y., A. Champhekar, S. L. Nutt, M. B. Elowitz, and E. V Rothenberg. 2013. Positive feedback between PU.1 and the cell cycle controls myeloid differentiation. Science (80-. ). 341: $670-673$.

23. Rosenbauer, F., K. Wagner, J. L. Kutok, H. Iwasaki, M. M. Le Beau, Y. Okuno, K. Akashi, S. Fiering, and D. G. Tenen. 2004. Acute myeloid leukemia induced by graded reduction of a lineage-specific transcription factor, PU.1. Nat Genet 36: 624-630.

24. Will, B., T. O. Vogler, S. Narayanagari, B. Bartholdy, T. I. Todorova, M. da Silva Ferreira, J. Chen, Y. Yu, J. Mayer, L. Barreyro, L. Carvajal, D. B. Neriah, M. Roth, J. van Oers, S.

Schaetzlein, C. McMahon, W. Edelmann, A. Verma, and U. Steidl. 2015. Minimal PU.1 reduction induces a preleukemic state and promotes development of acute myeloid leukemia. Nat Med 21: 1172-1181.

25. Ziliotto, R., M. R. Gruca, S. Podder, G. Noel, C. K. Ogle, D. A. Hess, and R. P. DeKoter. 2014. PU.1 promotes cell cycle exit in the murine myeloid lineage associated with downregulation of E2F1. Exp Hematol 42: 204-217 e1. 26. Houston, I. B., M. B. Kamath, B. L. Schweitzer, T. M. Chlon, and R. P. DeKoter. 2007. Reduction in PU.1 activity results in a block to B-cell development, abnormal myeloid proliferation, and neonatal lethality. Exp Hematol 35: 1056-1068.

27. Solomon, L. A., S. Podder, J. He, N. L. Jackson-Chornenki, K. Gibson, R. G. Ziliotto, J. Rhee, and R. P. DeKoter. 2017. Coordination of myeloid differentiation with reduced cell cycle progression by PU.1 Induction of microRNAs targeting cell cycle regulators and lipid anabolism. 
Mol. Cell. Biol. 37.

28. Morita, S., T. Kojima, and T. Kitamura. 2000. Plat-E: an efficient and stable system for transient packaging of retroviruses. Gene Ther 7: 1063-1066.

29. Puchalski, R. F., and D. K. Jasper. 1985. Sodium hypochlorite as a tissue solubilizing agent compatible with liquid scintillation counting. Int. J. Appl. Radiat. Isot. 36: 543-546.

30. Folch, J., M. Lees, and G. Sloane Stanley. 1957. A simple method for the isolation and purification of total lipides from animal tissues. J. Biol. Chem. 226: 497-509.

31. Livak, K. J., and T. D. Schmittgen. 2001. Analysis of relative gene expression data using real-time quantitative PCR and the 2(-Delta Delta C(T)) Method. Methods 25: 402-408.

32. Kamath, M. B., I. B. Houston, A. J. Janovski, X. Zhu, S. Gowrisankar, A. G. Jegga, and R. P. DeKoter. 2008. Dose-dependent repression of T-cell and natural killer cell genes by PU.1 enforces myeloid and B-cell identity. Leukemia 22: 1214-1225.

33. Li, J. J., H. Wang, J. A. Tino, J. A. Robl, T. F. Herpin, R. M. Lawrence, S. Biller, H. Jamil, R. Ponticiello, L. Chen, C. H. Chu, N. Flynn, D. Cheng, R. Zhao, B. Chen, D. Schnur, M. T. Obermeier, V. Sasseville, R. Padmanabha, K. Pike, and T. Harrity. 2007. 2-hydroxy-Narylbenzenesulfonamides as ATP-citrate lyase inhibitors. Bioorg Med Chem Lett 17: 3208-3211. 34. Comerford, S. A., Z. Huang, X. Du, Y. Wang, L. Cai, A. K. Witkiewicz, H. Walters, M. N. Tantawy, A. Fu, H. C. Manning, J. D. Horton, R. E. Hammer, S. L. Mcknight, and B. P. Tu. 2014. Acetate dependence of tumors. Cell 159: 1591-1602.

35. Kuhajda, F. P., E. S. Pizer, J. N. Li, N. S. Mani, G. L. Frehywot, and C. A. Townsend. 2000. Synthesis and antitumor activity of an inhibitor of fatty acid synthase. Proc. Natl. Acad. Sci. 97: 3450 LP-3454.

36. Bhagavan, N. V., and C.-E. Ha. 2011. Lipids I. In Essentials of Medical Biochemistry Elsevier. 191-207. 

Hirabayashi. 1997. Expression cloning and characterization of a cDNA encoding a novel membrane protein required for the formation of O-acetylated ganglioside: a putative acetyl-CoA

432 transporter. Proc. Natl. Acad. Sci. U. S. A. 94: 2897-902.

433 38. Hirabayashi, Y., A. Kanamori, K. H. Nomura, and K. Nomura. 2004. The acetyl-CoA 434 transporter family SLC33. Mol. Aspects Med. 34: 586-589.

435 39. Jonas, M. C., M. Pehar, and L. Puglielli. 2010. AT-1 is the ER membrane acetyl-CoA 436 transporter and is essential for cell viability. J. Cell Sci. 123: 3378-88.

437 40. Borgese, N. 2016. Getting membrane proteins on and off the shuttle bus between the 438 endoplasmic reticulum and the Golgi complex. J. Cell Sci. 129: 1537-1545.

439 41. Staber, P. B., P. Zhang, M. Ye, R. S. Welner, C. Nombela-Arrieta, C. Bach, M. Kerenyi, B. 440 A. Bartholdy, H. Zhang, M. Alberich-Jorda, S. Lee, H. Yang, F. Ng, J. Zhang, M. Leddin, L. E.

441 Silberstein, G. Hoefler, S. H. Orkin, B. Gottgens, F. Rosenbauer, G. Huang, and D. G. Tenen.

442 2013. Sustained PU.1 levels balance cell-cycle regulators to prevent exhaustion of adult

443 hematopoietic stem cells. Mol Cell 49: 934-946.

444 42. Aguilar, V., and L. Fajas. 2010. Cycling through metabolism. EMBO Mol Med 2: 338-348.

445 43. Lee, I. H., and T. Finkel. 2013. Metabolic regulation of the cell cycle. Curr Opin Cell Biol $446 \quad 25: 724-729$.

447 44. Sivanand, S., I. Viney, and K. E. Wellen. 2018. Spatiotemporal Control of Acetyl-CoA 448 Metabolism in Chromatin Regulation. Trends Biochem. Sci. 43: 61-74. 


\section{Figure Legends}

\section{Figure 1. Regulation of cell cycle progression in cultured BN cells by ACL inhibition and} acetyl-CoA supplementation. A) Representative cell cycle analysis of BN cells $48 \mathrm{hr}$ after start of culture. B) Cell cycle analysis of BN cells cultured with $55 \mu \mathrm{M}$ BMS for $48 \mathrm{hr}$. C) Cell cycle analysis of BN cells cultured with $55 \mu \mathrm{M}$ BMS and $100 \mu \mathrm{M}$ acetyl-CoA for $48 \mathrm{hr}$. D) Quantitation of the frequency of cells in S-phase for four experiments as shown in representative panels B and C. Statistical analysis was performed by paired $t$-test $(* p<0.05)$.

\section{Figure 2. Regulation of cell cycle progression in cultured BN cells by ACL inhibition and} acetate supplementation. A) Representative cell cycle analysis of BN cells $48 \mathrm{hr}$ after start of culture. B) Cell cycle analysis of BN cells cultured with $55 \mu \mathrm{M}$ BMS for $48 \mathrm{hr}$. C) Cell cycle analysis of BN cells cultured with $55 \mu \mathrm{M}$ BMS and $25 \mathrm{mM}$ acetate for $48 \mathrm{hr}$. D) Quantitation of the frequency of cells in S-phase for four experiments as shown in representative panels B and C. Statistical analysis was performed by paired $t$-test $(* * p<0.01)$.

\section{Figure 3. Regulation of cell cycle progression in cultured iBN cells by PU.1 induction and} acetyl-CoA supplementation. A) Representative cell cycle analysis of iBN cells $48 \mathrm{hr}$ after start of culture. B) Cell cycle analysis of iBN cells cultured with $1000 \mathrm{ng} / \mathrm{ml}$ doxycycline for $48 \mathrm{hr}$. C) Cell cycle analysis of BN cells cultured with $1000 \mathrm{ng} / \mathrm{ml}$ doxycycline and $100 \mu \mathrm{M}$ acetyl-CoA for $48 \mathrm{hr}$. D) Quantitation of the frequency of cells in S-phase for four experiments as shown in representative panels B and C. Statistical analysis was performed by paired $t$-test $(* p<0.05)$. E) Cell cycle analysis of BN cells cultured with $1000 \mathrm{ng} / \mathrm{ml}$ doxycycline and $25 \mathrm{mM}$ acetate for $48 \mathrm{hr}$. 
473 F) Quantitation of the frequency of cells in S-phase for four experiments as shown in representative

474 panels B and E. Statistical analysis was performed by paired $t$-test $(* p<0.05)$.

475

476

477

Figure 4. Regulation of cell cycle progression in cultured BN cells by FAS inhibition and

478

acetyl-CoA supplementation. A) Representative cell cycle analysis of BN cells $48 \mathrm{hr}$ after start

479 of culture. B) Cell cycle analysis of BN cells cultured with $10 \mu \mathrm{g} / \mathrm{ml} \mathrm{C75}$ for $48 \mathrm{hr}$. C) Cell cycle

480

analysis of BN cells cultured with $10 \mu \mathrm{g} / \mathrm{ml} \mathrm{C75}$ and $100 \mu \mathrm{M}$ acetyl-CoA for $48 \mathrm{hr}$. D) Quantitation

481 of the frequency of cells in S-phase for four experiments as shown in representative panels B and

482 C. Statistical analysis was performed by paired $t$-test $(* p<0.05)$.

483

484

Figure 5. Regulated incorporation of $\left[{ }^{3} \mathbf{H}\right]$-acetyl-CoA into cultured BN cells. A) Incorporation

of $[3 \mathrm{H}]$-acetyl-CoA into cultured $\mathrm{BN}$ cells. $\mathrm{BN}$ cells were incubated for $24 \mathrm{hr}$ with $0.5 \mu \mathrm{Ci}\left[{ }^{3} \mathrm{H}\right]-$

486 acetyl-CoA. DPM were determined in the supernatant and solubilized cell pellets. Statistics were

487 determined using one-way ANOVA with Tukey's multiple comparisons test, $p<0.05(\mathrm{n}=6)$. B)

488 Increased incorporation of $[3 \mathrm{H}]$-acetyl-CoA into cultured $\mathrm{BN}$ cells upon ACL inhibition. BN cells

489 were treated with (right bar) or without (middle bar) $55 \mu \mathrm{M}$ BMS and incubated for 24 hr with 0.5

$490 \mu \mathrm{Ci}\left[{ }^{3} \mathrm{H}\right]$-acetyl-CoA. DPM were determined in solubilized cell pellets. Data is presented as mean

$491 \pm$ SEM, one-way ANOVA with Tukey's multiple comparisons test, $p<0.05, \mathrm{n}=7$. C) Decreased

492 incorporation of [3H]-acetyl-CoA into cultured $\mathrm{BN}$ cells upon BMS and acetate but not BMS and

493 Acetyl-CoA supplementation. BN cells were supplemented with either $25 \mathrm{mM}$ acetate (third bar)

494 or $100 \mu \mathrm{M}$ acetyl-CoA (fourth bar) at the same time as $55 \mu \mathrm{M}$ BMS and incubated for $24 \mathrm{hr}$ with

$4950.5 \mu \mathrm{Ci}\left[{ }^{3} \mathrm{H}\right]$-acetyl-CoA. DPM were determined in solubilized cell pellets. Data are presented as 
mean \pm SEM. Statistics were determine using one-way ANOVA with Tukey's multiple

497 comparisons test, $* p<0.05(\mathrm{n}=5$ experiments).

Figure $6\left[{ }^{3} \mathrm{H}\right]$-acetyl-CoA is incorporated in both lipids and histones. A) BN cells were incubated with $\left[{ }^{3} \mathrm{H}\right]$-acetyl-CoA for 24 hours followed by enrichment of lipids or histones as described in Materials \& Methods. Normalized DPM was determined using liquid scintillation counting and correction for volume. Data are presented as mean $\pm \mathrm{SEM}$, one-way ANOVA with

Tukey's multiple comparisons test, $p<0.05, \mathrm{n}=5$. B) Increased incorporation of $\left[{ }^{3} \mathrm{H}\right]$-acetyl-CoA into lipids upon ACL inhibition. BN cells were treated with (right bar) or without (middle bar) 55 $\mu \mathrm{M}$ BMS and incubated for $24 \mathrm{hr}$ with $0.5 \mu \mathrm{Ci}\left[{ }^{3} \mathrm{H}\right]$-acetyl-CoA. DPM were determined in lipid extracts. Data are presented as mean \pm SEM, one-way ANOVA with Tukey's multiple comparisons test, ${ }^{*} p<0.05, * * p<0.01, \mathrm{n}=5$ experiments.

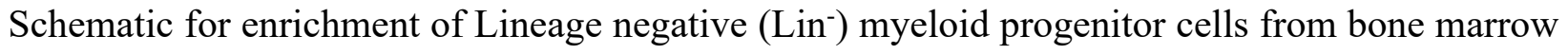
using magnetic bead depletion. B) Depletion of CD11 b cells from bone marrow. Left panel shows frequency of $\mathrm{CD}_{1} 1 \mathrm{~b}^{+}$cells in unfractionated bone marrow. Right panel shows frequency of

514 containing $10 \mathrm{ng} / \mathrm{ml} \mathrm{M-CSF}$. Representative photomicrographs were taken at 2 (left panel), 4 515 (middle panel), and 6 (right panel) days. Scale bar indicates $20 \mu \mathrm{m}$. D, E) Acly mRNA transcript 516 levels decrease during macrophage differentiation. Using RT-qPCR, mRNA levels of Acly in the 517 column separated BMCs were determined for day 2, 4, and 6 time points. Acly transcript levels 518 were normalized to $\beta 2 m$ (D) or Adgrel (E). Statistical analysis was performed using two-way $519 \quad$ ANOVA, $* p<0.05, \mathrm{n}=3$ experiments. 

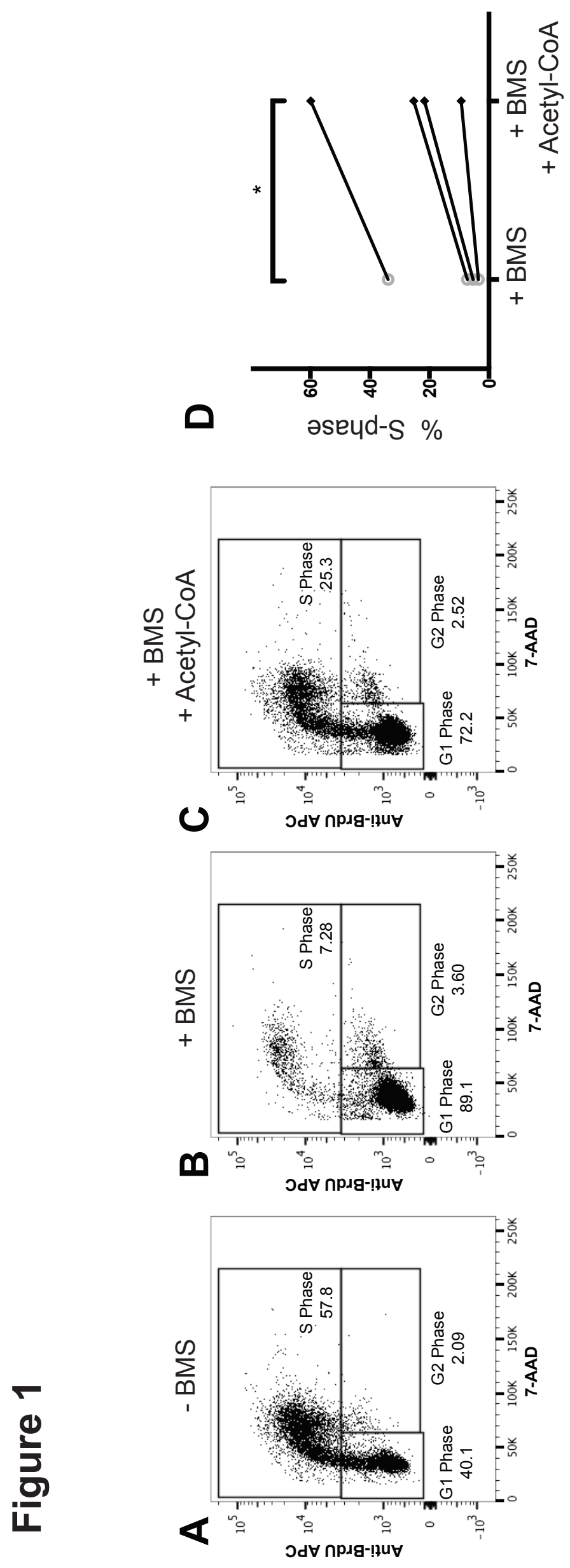

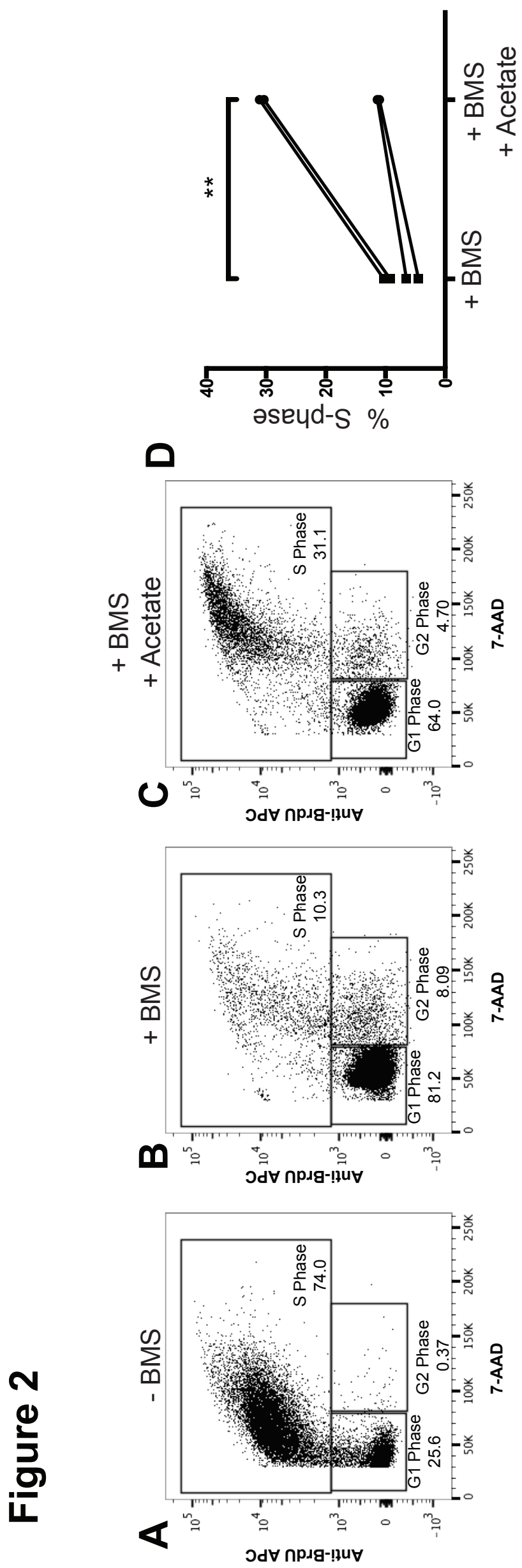
Figure 3
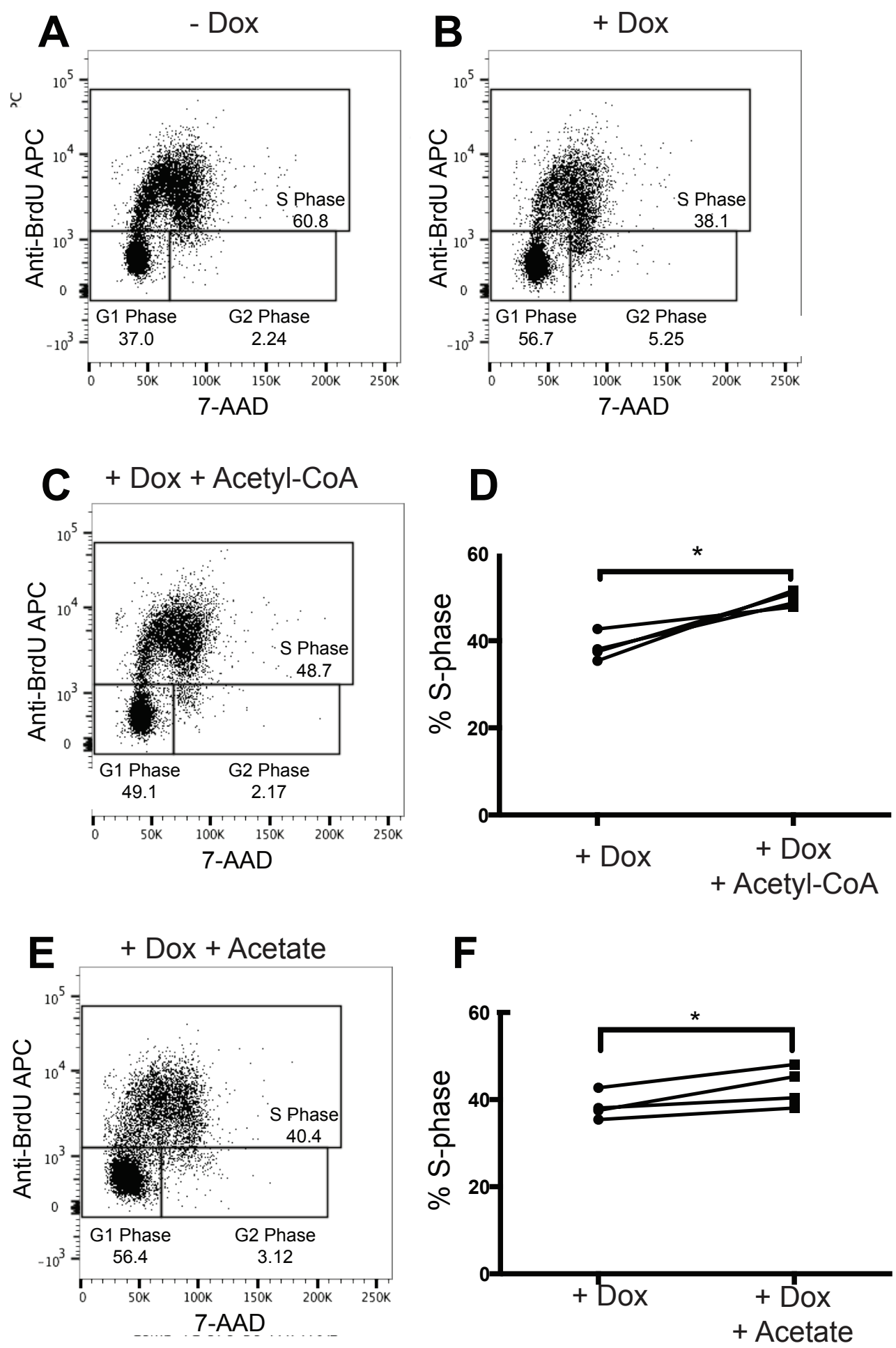

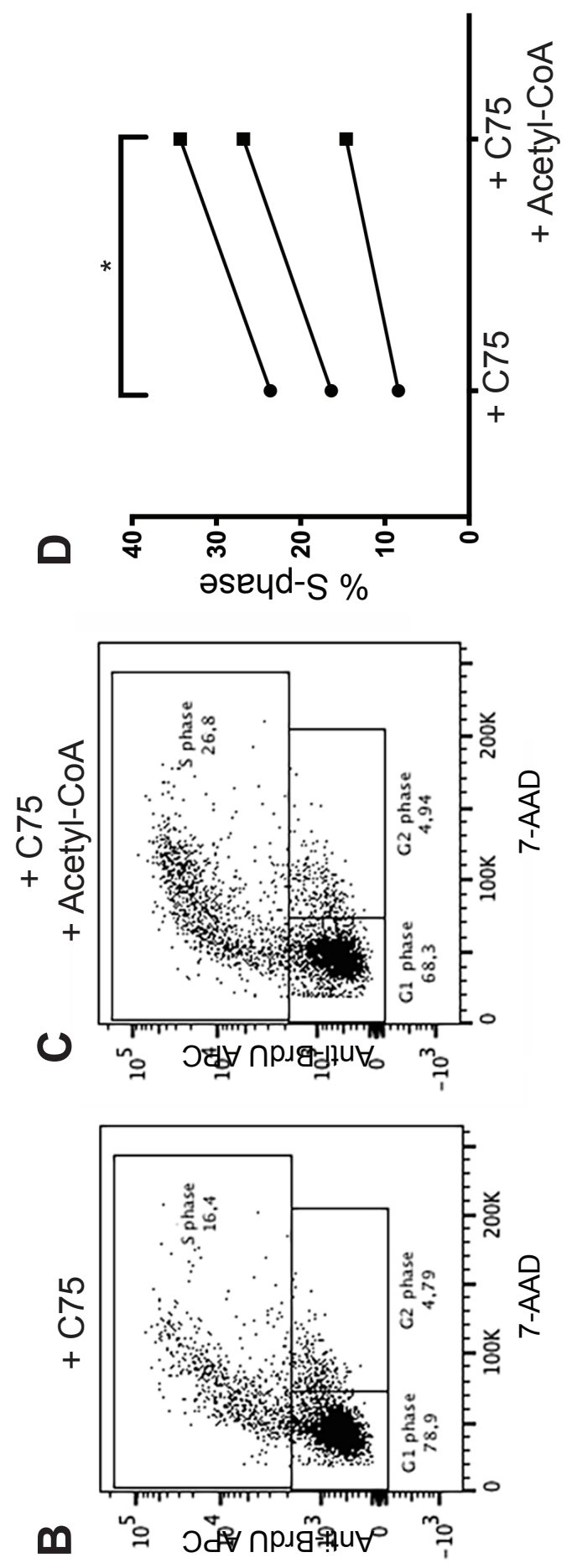

올

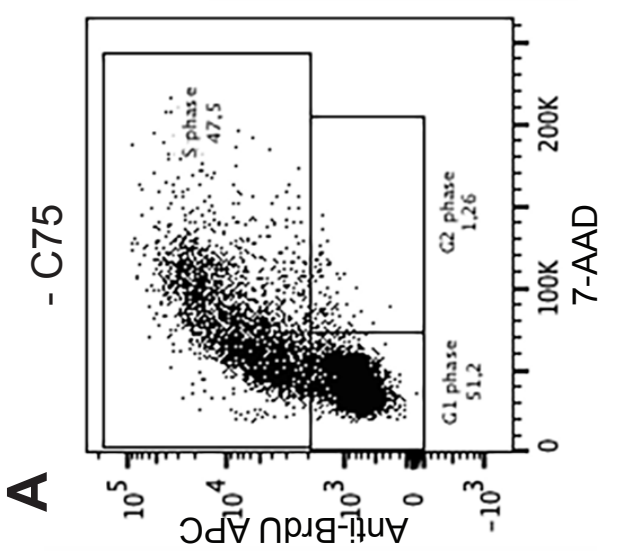




\section{Figure 5}

A

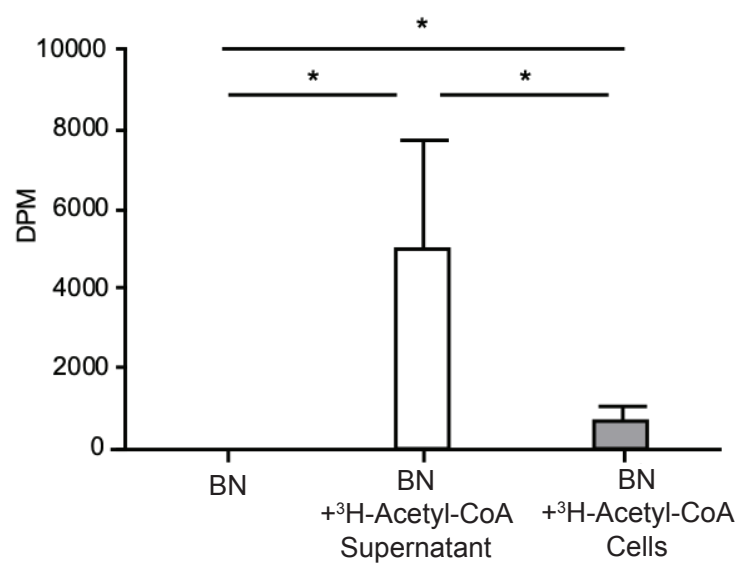

C

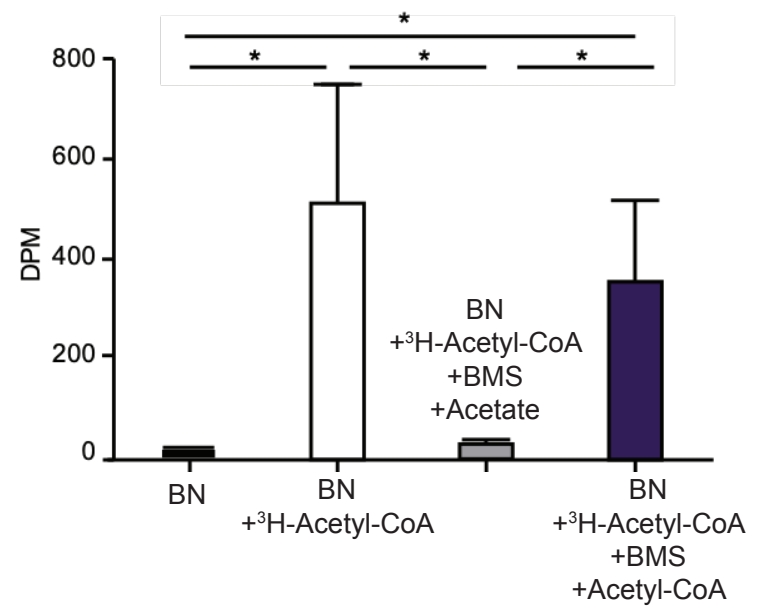

\section{B}

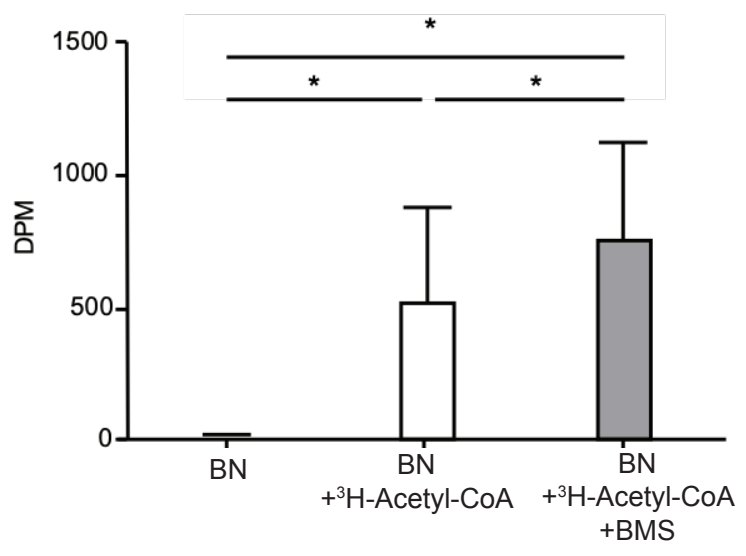




\section{Figure 6}

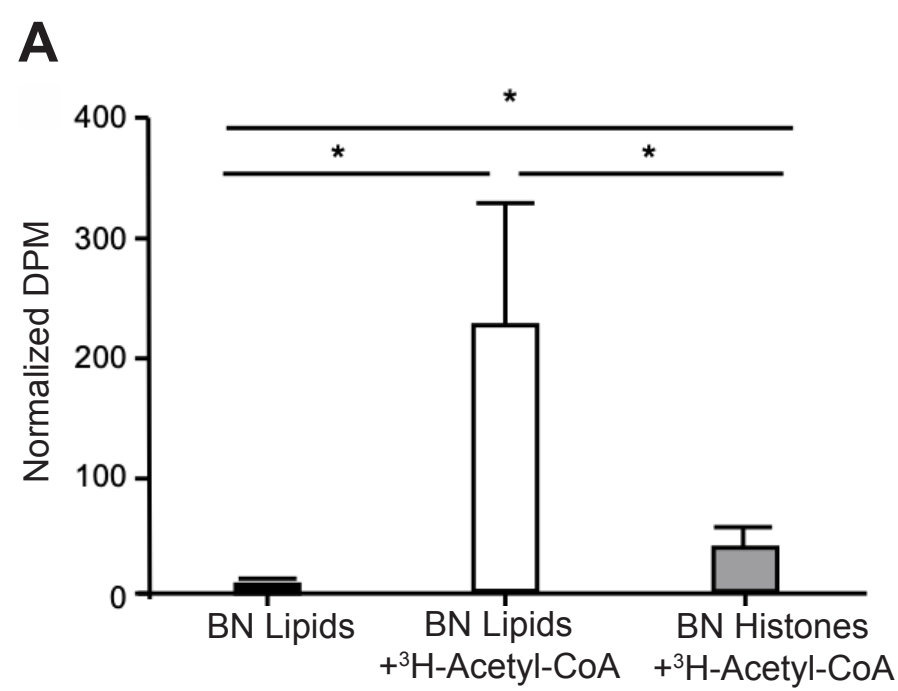

B

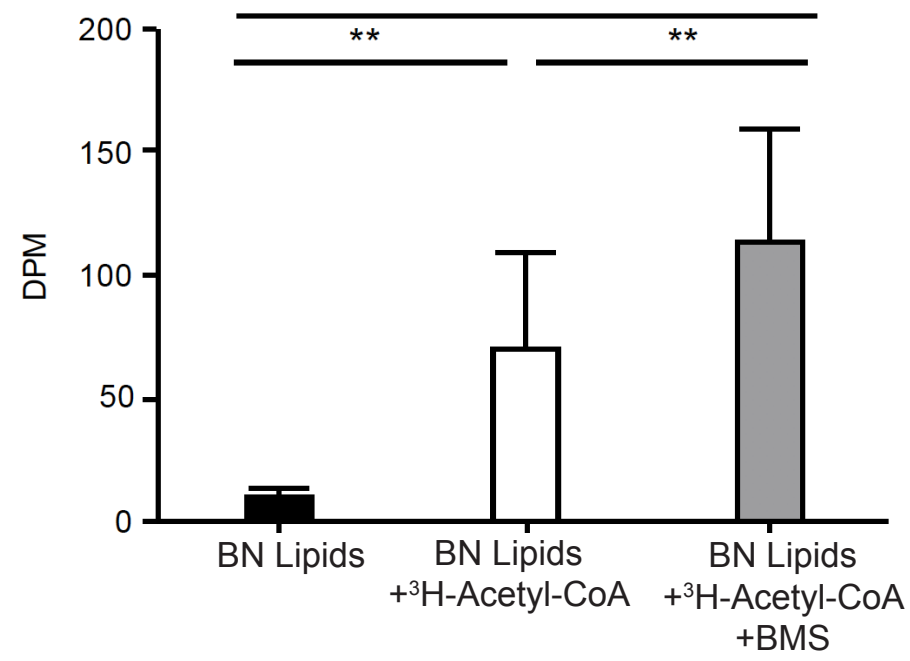



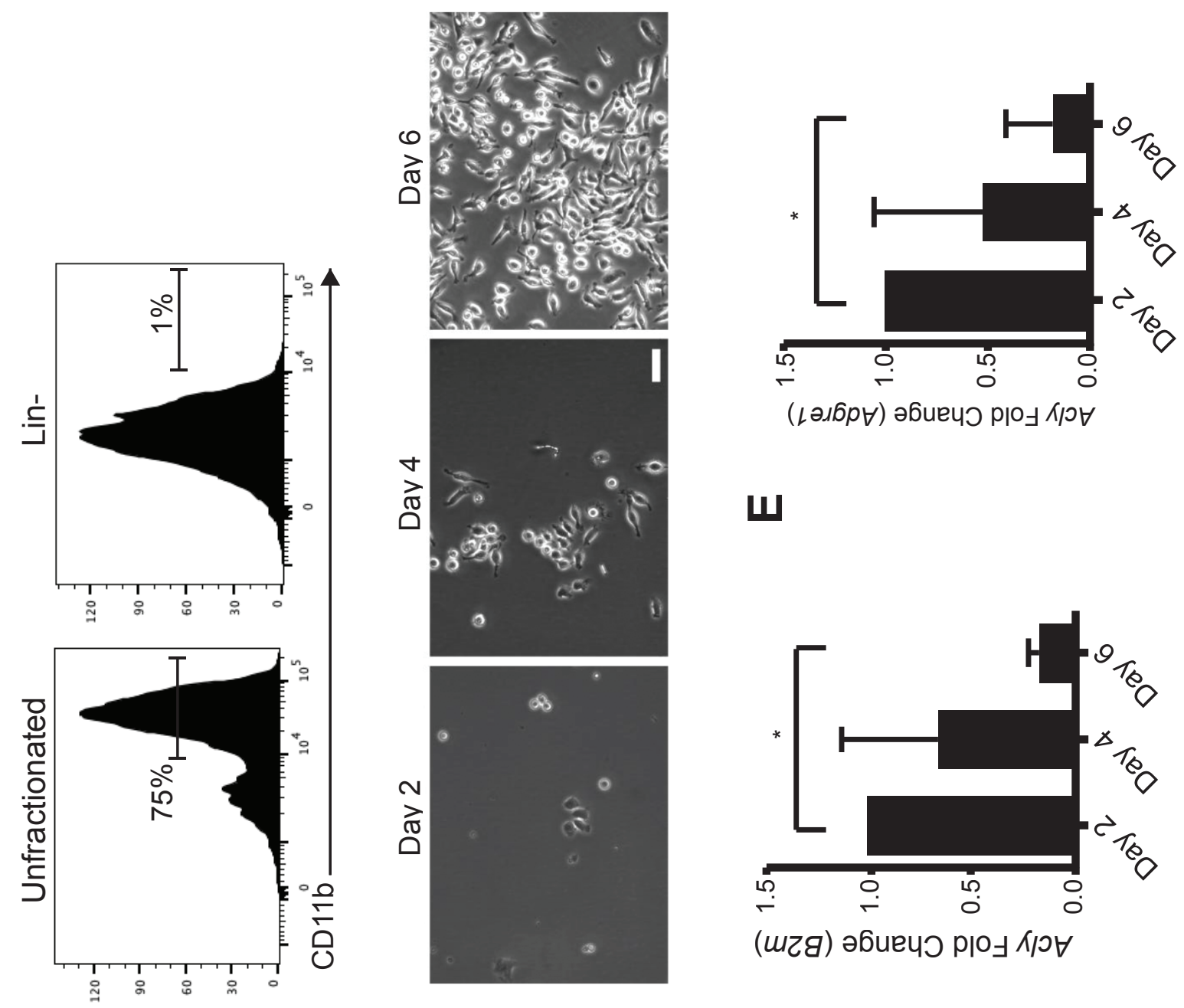

II

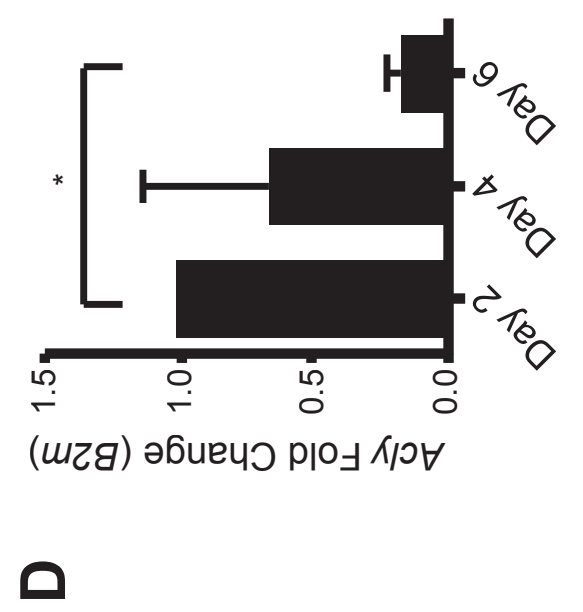

ก

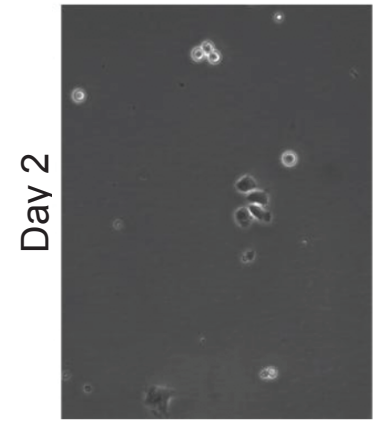

0

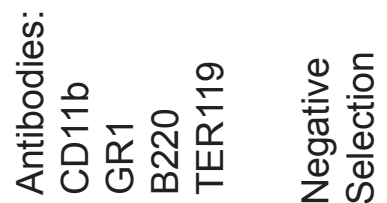

告

$\frac{1}{0}$
0
1
1
$\frac{1}{3}$
0
$\frac{0}{3}$
$\frac{1}{3}$
0

온

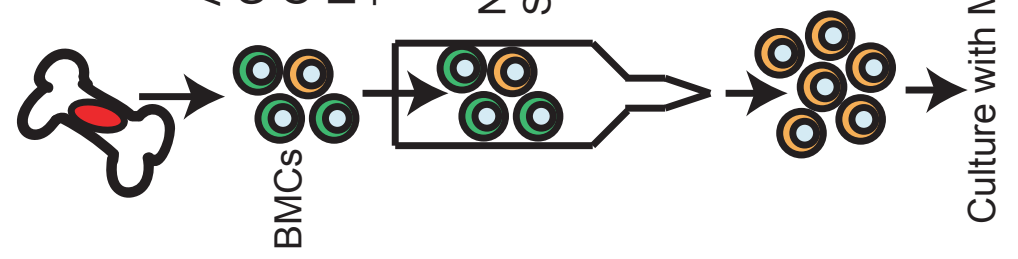




\section{Supplemental Table 1 - Primer sequences}

\begin{tabular}{|l|l|}
\hline Primer Name & Sequence \\
\hline Acly forward & 5'-CCAGTGAACAACAGACCTATGA- ' \\
\hline Acly reverse & 5'-AATGCTGCCTCCAATGATG- ' \\
\hline$B 2 m$ forward & 5'-TGGCTCACACTGAATTCACCCCCA-3' \\
\hline B2m reverse & 5'-TCTCGATCCCAGTAGACGGTCTTGG-3' \\
\hline Adgrel forward & 5'-GTGGTCATAATCTCTGCTTCTGT-3' \\
\hline Adgre 1 reverse & 5'-AAACTCCAGATAAACCCCGTC-3' \\
\hline
\end{tabular}

